Gazi University
Journal of Science
http://dergipark.gov.tr/gujs

\title{
Modelling AI in Architectural Education
}

\author{
Lale BASARIR * \\ Izmir University of Economics, Department of Architecture, Sakarya Caddesi, No:156, 35330 Balçova - İzmir / Türkiye
}

Highlights

- This paper focuses on the need to integrate AI in Architectural education.

- A research-based undergraduate course model is proposed.

- An evaluation of the learning outcomes and the future direction for the course are discussed.

\section{Article Info}

Received: 09 July 2021 Accepted: 29 Dec 2021

\section{Keywords}

Artificial intelligence in architecture.

AI in architectural

education,

Curriculum

Learning

\begin{abstract}
This work displays an outlook on major questions concerning the integration of Artificial Intelligence (AI) in Architectural education. Gradually, part of the domain knowledge and hard skills become either irrelevant or insufficient by the time the students graduate. This paper suggests that integrating AI in the architectural design curriculum is beneficial for raising designers' awareness of all areas of architectural design, in the form of input, process, and output. The study views consecutive learning experiences in a continuum and explores the potentials of integrating AI applications and techniques in architectural education, and how architectural design practice may benefit from it. Consequently, it provides insights into how architectural design education may transform itself considering the future impact of $\mathrm{AI}$ on the Architecture Engineering Construction (AEC) industry.
\end{abstract}

\section{INTRODUCTION}

Educational institutions around the globe are facing a fast pace of technological advances causing much of the domain knowledge and hard skills to become irrelevant or insufficient by the time the students graduate. This phenomenon is not only due to the rapid changes in businesses and/or practices but is also a consequence of the change in curricula of $\mathrm{k} 12$ and earlier education [1]. Skills previously classified as extraordinary are becoming ordinary, due to the mastery of computation, automation, and generative capabilities both for software and hardware. Therefore the need to develop a framework for continuously updated architectural education is not bound by skill improvements. We also need to develop a theoretical base on which the new breed of architects can operate. Though the same issues have been experienced successively with the advent of Computer-Aided Design (CAD) and Building Information Modeling (BIM), the current architectural education is expected to tackle the present and future challenges of the industry while taking a proactive role in restructuring it.

This article addresses the issues of rapid technological changes affecting architectural design within the scope of AI. Starting with informing about the motivation of this study, the paper reflects upon a small step taken as an effort to introduce the basics of AI to architectural students. The second part lays out the questioning of why AI should be introduced to architectural education (AE) by introducing a background for the discussion. The scope that AI refers to in this article is depicted in the third part where the content delivery is explained. The paper does not include a further discussion on the definition of AI. The fourth section articulates the understanding that is reached upon completing the experimentation of developing and running the research-based course on AI in Architecture. The 
conclusion section gives an overview of this experimentation and proposes further considerations left for improvement.

Just as BIM has transformed the Architecture Engineering Construction (AEC) industry [2-4], AI is changing how jobs are defined, categorized, and assigned in the industry [5]. Parallel to the advances in AI applications, architectural education needs to evaluate the potentials and challenges. With the adoption of scripting and visual programming tools in design workflows, parametric definitions, components/nodes, and links/wires/connections with input and output flows have displaced form and dimensions. Similarly, the Cartesian logic of representation in architecture will inevitably change [6]. One example of the change in Cartesian logic of representation is that while we still teach technical drawing by conventions and orthographics, the industry AEC industry is rapidly exercising collaboration on object-based virtual buildings. One possible approach for educational institutions is to offer elective courses to leverage their programs with advanced or up-to-date content [7]. Therefore, there should be in-depth research on how to update architectural design education for the mentioned transformative pace of change. As a small step forward in terms of adapting to the approaching transformation this study investigates the challenges of integrating AI into the architectural study through hands-on experimentation, designed for and applied to the first cycle (undergraduate) architectural curriculum.

\section{A LOGICAL BASIS FOR INTEGRATION OF AI IN ARCHITECTURE}

Before discussing how Artificial Intelligence (AI) should be taught within Architectural education, we should ask why it should be taught. Architectural design is a problem-solving methodology that develops with tacit knowledge described by Polanyi as knowing more than we can tell [8]. Tacit knowledge is an accumulation of refined approaches to problem-solving, as well as integration of intangible factors and insights. This study inquires within this experimental course whether AI can be accommodating the tools and techniques that tacit knowledge of architecture might be inherited through machines. Architectural knowledge has unique qualities which require both qualitative and quantitative analyses. Therefore there is an ongoing discussion whether 'architectural knowledge' refers to an autonomous scientific discipline [9]. The distinction between architectural practice and theory may be that architectural practice cannot be considered simply as the application of what is put forward in the theoretical field, or vice versa, as the theoretical expression of what is practical. The practical field gradually builds up knowledge for production, in various contexts, and remains mostly at the personal level. With this aspect, it can be partially coded and made open [10].

Architecture has an important role in creating the built environment, although there are many other stakeholders and components. However, the architectural knowledge required in practice is gravitating towards greater dependency on the expertise of specialists rather than the architects'.

Recently, building performance evaluation studies have developed within the scope of building physics measurements, and when compared, limited objective evaluations have been made integrating criteria regarding the users of space $[11,12]$. These evaluations were limited to physical qualities and did not develop in the direction of measuring and evaluating the subjective criteria involved in the design process of the architectural action. However, one of the qualities that distinguish the act of architecture from other fields of expertise is that the specialization process of this profession is based on experience transfer and master-apprentice relationship. Yona Friedman classifies architecture as a vocation that is prenticable (can be learned through apprenticeship) [13]. In an "objective/scientific system", regardless of the qualifications and personalities of the practitioners, the result obtained by taking each predefined step bears no clear trace of the practitioners themselves. On the contrary, it is seen that there are no predefined steps in the "intuitive system" that he exemplifies for Architecture, and that communication and symbols are defined where all practitioners can draw different results from each other [14]. However, Friedman's main discomfort is that it is not clear how much the architect takes responsibility and who bears the responsibility of the "bad design" between the user of the space and the built environment proposal that is deemed appropriate for that user. This claim or question is still valid today. Friedman defined architecture as a "repertoire" of design that bears all possible solutions for a defined problem where all links of units/elements with each other are defined with a warning system. Yet architecture 
does not have precise rules and therefore the definition of the problem does not allow for a clear prediction of the possible solution. Therefore design evaluation assessment in education still stays rather subjective.

Upon splitting of engineering and architectural expertise, the mathematics of architectural design gravitated from structural aspects, towards patterns, topologies, geometries, orientation, and networks [15]. Therefore, an increasingly quantitative approach was taken towards modularity, proportional relations, and environmental considerations. This quantitative approach led to an understanding and maturity of architectural creation, not merely based on experience, but some tacit knowledge that may well be translated into computation. Architectural researchers investigated whether machines could mimic skilled architects if instructed step-by-step on specific problem-solving skills attributed to architects. In the design domain, there were two different approaches to AI. While one tendency was to expect AI to exhibit human-level intelligence in performing tasks associated with human capabilities, the other was to envision machines as being equally capable as intelligent machines, although they were not necessarily intelligent [16]. The Generator project, a reconfigurable and responsive architecture changing based on personal interactions, envisioned and briefed by Cedric Price was expected to have "a mind of its own" [17]. Therefore, in the case of architectural design, AI was mostly envisioned and explored within the domain of automated space planning [18]. Several works on automated layout planning and space allocation problems [19] brought significant advances as did Muther's Systematic Layout Methodologies (SLM) developed for plant layout designs [20,21]. Several computational methods to produce and evaluate plans have been built and used in the architectural domain. These computational methods used in space planning problems at various scales include Half plan, K3d tree, Shape Grammar, Blocking, One-to-one assignment, Slice tree structure for generation and Quadratic Assignment Problem, Interactive Evaluation, Adjacency Matrix, and Graph Theory for evaluation purposes [22].

Applications of AI in the architectural design domain were concerned with logic and search. Therefore analysis of objectives was bound by location and arrangements of spatial configurations. Activity units and locational attributes were used to define design decisions [23]. As Gero anticipated, AI research in this domain is tending towards automating routine tasks and moving beyond detail design towards the conceptual design phase [24].

As stated earlier, the expertise gained by experience (tacit knowledge) gradually becomes a transferable knowledge that can be measured and reproduced step by step with the development of digital tools. For example, before the digital tools, integration of geographical and climate data in both the orientation of buildings and decision processes regarding the plan scheme was completely based on the experience of the architect and the transferred knowledge. However, it is not specific knowledge or skills unique to architects anymore. Digital tools also allow non-architects to make these evaluations. Such digitization of profession-specific expertise can project onto objective evaluation/assessment of the built environment. Therefore, objective assessment is expected to greatly change the practice of the profession and the way it is passed on to new generations. With the attempt to strip architecture to its core value, we may start to see the computer-aided designer gradually minimizing its impact zone within AEC while on the other hand refining its essential raison d'être. After all, architects can still design with pencils [25]. This is when AI in architecture needs to be explored. The gap of a sound evaluation of design output can be filled with the enormous analytical capabilities of machines/AI. We have already begun to see cloud platforms designed to provide non-experts with the opportunity to create architectural designs [26].

On the other hand, the AEC industry is not yet considered to have transformed itself digitally and claimed to suffer from "under-digitization and fragmentation" [27]. The change expected may require a reassessment of the boundaries and definition of architectural profession and education within the domain of artificial intelligence (AI) tools [28]. Therefore within the scope of this research, AI is expected to shed light on how it can augment the architect to gradually decipher the core implicit knowledge of Architecture. When AI is considered as a learning machine and gradually becomes able to capture profession-specific expertise, architects may need to rebuild the architecture from its core. The 
author suggests that it is time for architects to try and understand the implications of these learning machines that may be able to learn even the tacit knowledge of architecture and practice it in the industry.

Machine learning research and applications in architectural design are rapidly developing, though they are not yet reaching readers explicitly, though. Models used in architectural machine learning applications are not yet clear and explainable. Tamke et al. discuss two cases of how architectural practices are influenced by machine learning (ML) tools, performance-based design, and fabrication [29]. Through these cases, they identify the challenges for machine learning and discuss that architectural applications of ML require unique tailoring for each project and that data collection, preprocessing of data and computational power are indeed important factors for ML in architectural practice. This is the case in general AI applications. However, we are beginning to see solutions for data preprocessing phases by automation and the use of learning models for the same purpose. Not having enough data is an important issue especially for Deep Learning (DL) applications, however, this is not true for all DL cases. The recent application reveals that the use of GANs in architectural layout creation does not require thousands of images as previously implied [30]. The basic principle of GAN carries a feedback loop that starts with a Generator that creates images based on a train set of data and a Discriminator that tells the real from fake leading to the imperfection of the Generator's creation process. The use of GANs in generative environments is growing with success generating floor plans and styles [31]. We consider GANs especially the most suitable application for architectural intelligence when generative purposes are the case since the learning mechanism is very similar to the way architect candidates are trained in design studios where they bring their design proposals and get desk critiques as feedback to improve their designs.

The objective of this research is to define how AI tools and architectural knowledge can be integrated to learn and practice architecture. Machines that can think or design have been imagined by many architects, engineers, and/or researchers. "The Architecture Machine" mentions the possibility of machines tracking people and building predictive models. Negroponte argues that machines can learn architecture through sampling and evaluation - without knowing the rules beforehand [32]. It is mentioned, within the scope of laboratory studies, about not only computer support that does what architects do naturally and effortlessly, but also the possibility of architectural design to be carried out together with more effective machine intelligence. Computation and/or artificial intelligence applications in architecture carried out with the focus of knowledge-based systems [33-36], produced rule-based systems containing if-then expressions. However, the focus of the course is not to create a knowledge base with expert systems, but to enable AI to learn from data with the use of learning models. Here, it is envisioned that expert knowledge is put into use during the phases of model improvement or supervised learning. Mustoe suggests three possibilities of using artificial intelligence in architecture which he lists as cognitive simulation, mainstream topics, and intelligent artifacts. He gives no chance to the first because cognitive simulation requires consciousness and even self-awareness and unfortunately this is "not possible". Second is an active research area, but may not contribute to architectural practice in the short term. He claims that the third possibility that he includes the expert systems is a runner-up and suggests a model [37] where 512 questions have been prepared and connected with their corresponding solutions. An expert system called Cortex, which contains the most frequently asked questions and responses of the knowledge base of architecture and works with a classification algorithm in the background, has been created. This work, which remained in the prototype stage, has depth in terms of examining architectural practice, but it does not bear the learning feature of artificial intelligence. Another artificial intelligence model application for design research uses artificial neural networks (ANNs), visual material and verbal expression describing it are matched, i.e. labeling and detailed definition, and then, the design that matches the problem definitions made by the user is found from a library [38].

Artificial intelligence applications and research in architecture have accelerated more efficiently in recent years [39]. Some researchers examine artificial intelligence tools within the scope of generative algorithms and their efficiency is used at the level of aiding designers at the architectural design phase and decision-making processes are expected to be under the control of the architect [40]. 
Deep learning (DL) models of AI need vast amounts of data to work efficiently. This has also been the case for architectural models. However, in a study in which Generative Adversarial Networks (GANs) are used as the DL model, the slow pace of development of architectural applications using deep learning models due to insufficient data is eliminated. This model can generate thousands of architectural plan charts and do this with a relatively small dataset [41]. In this study, plan charts are matched with colored and semantic maps, and learning is done through this train set. In this model, color schemes are given as input, and realistic plan layouts are obtained as output. However, in some cases, the model can produce "better" suggestions than the samples it is trained on. A similar study was extended and implemented by Chaillou with successful outputs [42]. Another AI application known as Pix2pix made in Berkeley AI research laboratory matches Image-to-Image and can transform simple sketches and schemes into realistic images such as building facades [43].

Besides generative applications, there are alternative studies that use the creative writing method in architectural education to create the design idea and integrate this method to improve the verbal definition of the design through a chat-bot called Nuncias [44]. Conceptual data acquired through this chatbot is then analyzed for a qualitative evaluation of the design process. The application prompts the designer with a starting question such as "what kind of a project is on your mind" and continues the conversation with the questions that the designer chooses from the predetermined answer options by recording and analyzing the answers. The data obtained at the end of the conversation is transferred to a text-based visual production application. A more recent study searching whether an architectural problem can be described as a brief to an AI model to extract preliminary design sketches [45] A transformer trained as a 12 billion parameter version of Generative Pre-trained Transformer version 3 (GPT-3) that learns from text to image pairs is a model called Dall-e the researchers of which are also working on the possible economic impact it might cause on certain work processes and professions [46] Dall-e transforms textual expressions into corresponding images. This is a skill that humans had and now machines can already do it in a fairly consistent fashion.

Relevant studies provide a base for the elective course. This experimental course also aims at developing a model based on recognizing patterns in architectural knowledge [47]. Thanks to technological developments in both hardware and software, instances where certain tasks are performed perfectly by artificial intelligence and more successfully than humans are seen in a wide range of domains. However, artificial intelligence systems cannot yet think. Deep learning models and increasingly large datasets are not enough for this and it does not have what we call "common sense" which is the ability to generalize, create and simulate abstract information [48]. Common sense and foresight are based on experience and are the most decisive of the distinctive qualities of architectural action hence human interaction. $\mathrm{AI}$ is trying to resolve issues of common sense and consciousness as the biggest challenge. For example, in the field of artificial intelligence, the learning models of a ten-year-old child or biology-based virtual characters with the basic common sense are being modeled by the US military DARPA agency [49].

This paper suggests that integrating AI in the architectural design curriculum will help raise designers' awareness of all areas of architectural design. Whether subject to an existential threat or exposed to an evolutionary process, the profession of Architecture will certainly go through a transformation due to technological advancements. The two possible futures envisioned for many professions existent today are worth examining [50]. While one scenario for more immediate change can be a complementary one in which technology continues to augment professionals, the second scenario might mean the complete replacement of today's professionals. In this latter vision, the tasks associated with skilled and experienced experts will increasingly be accomplished by machines through the "dismantling of professions".

Should AI learn from the construction industry, by scanning and recognizing patterns of which we human architects are not explicitly aware? Does architecture respond efficiently to the needs and preferences of occupants? Will AI applications suggest only some extended and enhanced version of BIM? These were among the questions addressed throughout the setup of the course. Upon deciding terms of content, the next major challenge was to design the pedagogical approach to introduce the basics of AI to architectural design students. 


\section{METHODOLOGY, A RESEARCH-BASED ELECTIVE COURSE}

This study describes an approach to a new elective course that ran consecutively for three semesters in two universities, undergraduate students in their third and fourth years with similar backgrounds. Based on previous experience of teaching a BIM course in undergraduate/first cycle education in XUniversity, the objectives of the course were set rather cautiously. Teaching AI is challenging, and designing a hybrid course balancing the concepts from two different domains (AI and Architecture) is even more so.

Running a research-based elective course, that aims to understand the core knowledge of architecture while exposed to techniques and tools of AI the question of common sense and consciousness comes into play. Within the scope of this research, concepts of common sense and consciousness in AI are considered correspondents of tacit knowledge in architectural design processes. The structure and methodology of the course are based on building a model that learns from the Architectural knowledge base.

The course was designed to highlight AI's potential to improve architectural practice and its reflection on architectural education. Taxonomy of tasks for AI in Architecture (Table 1) exercises the analyses of architecture for a hypothetical AI model that learns architecture. For each step, the students defined tasks that the hypothetical AI architect should perform, and through this taxonomy, they were able to analyze each task of interest (TOI) in terms of whether they required Human Intervention (HI) and/or were suitable for Robotic Process Automation (RPA) and/or could be performed with AI.

Table 1. Taxonomy of tasks for AI in Architecture

\begin{tabular}{|c|c|c|c|c|c|c|c|}
\hline \multirow{2}{*}{$\begin{array}{c}\text { Project Phase } \\
\text { Task of Interest }\end{array}$} & \multicolumn{3}{|c|}{\begin{tabular}{|l|} 
Classification of Tasks \\
\end{tabular}} & \multirow{2}{*}{\begin{tabular}{|c|} 
Input \\
Description of \\
Required Data
\end{tabular}} & \multicolumn{2}{|c|}{ Process } & \multirow{2}{*}{\begin{tabular}{|l}
\multicolumn{1}{c}{ Output } \\
Description of \\
Desired \\
Output
\end{tabular}} \\
\hline & \begin{tabular}{|l} 
Robotic \\
Process \\
Automatio \\
$n($ RPA $)$ \\
\end{tabular} & \begin{tabular}{|l|} 
Artificial \\
Intelligence \\
$(A I)$
\end{tabular} & \begin{tabular}{|c|} 
Requires \\
Human \\
Interventi \\
on $($ RHI $)$ \\
\end{tabular} & & $\begin{array}{l}\text { Suggested } \\
\text { Tools }\end{array}$ & $\begin{array}{l}\text { Suggested } \\
\text { techniques }\end{array}$ & \\
\hline $\begin{array}{l}\text { Listening to the } \\
\text { Client }\end{array}$ & true /false & true /false & true /false & $\begin{array}{l}\text { Data acquired } \\
\text { from the } \\
\text { audio file of } \\
\text { clients' } \\
\text { describing the } \\
\text { project }\end{array}$ & $\begin{array}{l}\text { Natural } \\
\text { Language } \\
\text { Processing } \\
\text { to read }\end{array}$ & $\begin{array}{l}\text { or Speech } \\
\text { Recognition } \\
\text { algorithms }\end{array}$ & $\begin{array}{l}\text { Transcription } \\
\text { of client's } \\
\text { needs }\end{array}$ \\
\hline $\begin{array}{l}\text { Transcription of } \\
\text { client's needs }\end{array}$ & true /false & true /false & true /false & Text data & GAN & $\mathrm{CNN}$ & $\begin{array}{l}\text { Image; Initial } \\
\text { sketches }\end{array}$ \\
\hline
\end{tabular}

The TOI defines the task that the model will perform to carry out the process that it belongs to. Input, process, and output columns are dedicated to defining the model in terms of what we feed the model with, which AI tools and techniques will be used and what we expect the model to yield as an output.

\subsection{Framework}

The teaching of this course is based on the educational design ladder (EDL) method by Wrigley and Straker [51]. The five order skill level building steps of EDL; knowledge comprehension, application, analyses, synthesis, and evaluation are considered while designing the topics, content delivery, learning modes, and assessments. As the ladder introduces a linear progress it was reinterpreted to serve the course that required reiterative loops at certain stages. For example, the flow of the course (Table 2) throughout the semester is based on EDL however the content delivery at certain levels required going back to lower levels to regain comprehensive modes. Evaluative and other assessment suggestions are not within the scope of this paper [52].

Table 2. The flow of the course based on EDL

\begin{tabular}{|l|l|l|l|l|l|l|}
\hline Levels of EDL & $\begin{array}{l}\text { Learning } \\
\text { Outcomes } \\
\text { (EDL) }\end{array}$ & $\begin{array}{l}\text { Topics in } \\
\text { Architecture }\end{array}$ & $\begin{array}{l}\text { Topics in } \\
\text { Artificial } \\
\text { Intelligence }\end{array}$ & Assignment & Environment & $\begin{array}{l}\text { Assignment } \\
\text { Objectives }\end{array}$ \\
\hline
\end{tabular}




\begin{tabular}{|c|c|c|c|c|c|c|}
\hline \multirow{3}{*}{$\begin{array}{l}\text { Knowledge } \\
\text { Comprehension }\end{array}$} & \multirow{3}{*}{$\begin{array}{l}\text { Knowledge of } \\
\text { terminology, } \\
\text { specific details, } \\
\text { and elements }\end{array}$} & \multirow{2}{*}{$\begin{array}{l}\text { Possible } \\
\text { contributions of } \\
\text { artificial } \\
\text { intelligence } \\
\text { implementations } \\
\text { to architectural } \\
\text { problem-solving } \\
\text { practices }\end{array}$} & Basics of AI & 1 & & $\begin{array}{l}\text { This assignment } \\
\text { provided a } \\
\text { warm-up to } \\
\text { focus on the } \\
\text { meaning of AI }\end{array}$ \\
\hline & & & \multirow{2}{*}{$\begin{array}{l}\text { History of AI, } \\
\text { Machine } \\
\text { Learning(ML) } \\
\text { and Deep } \\
\text { Learning (DL) }\end{array}$} & 2 & $\begin{array}{l}\text { Anaconda } \\
\text { Navigator and } \\
\text { Jupyter }\end{array}$ & $\begin{array}{l}\text { Understanding } \\
\text { data }\end{array}$ \\
\hline & & $\begin{array}{l}\text { Convergence of } \\
\text { Architecture and } \\
\text { Computer } \\
\text { Science } \\
\end{array}$ & & 3,4 & Python IDE & $\begin{array}{l}\text { Classification } \\
\text { methods and } \\
\text { libraries }\end{array}$ \\
\hline Application & \multirow[b]{2}{*}{$\begin{array}{l}\text { Knowledge of } \\
\text { classifications } \\
\text { and categories, } \\
\text { principles and } \\
\text { generalizations }\end{array}$} & \multirow{2}{*}{$\begin{array}{l}\text { Training } \\
\text { principles of } \\
\text { artificial } \\
\text { intelligence and } \\
\text { role and } \\
\text { significance of } \\
\text { data towards } \\
\text { solving } \\
\text { architectural } \\
\text { problems }\end{array}$} & $\begin{array}{l}\text { Training } \\
\text { machines on } \\
\text { datasets using } \\
\text { models }\end{array}$ & 5 & Python IDE & $\begin{array}{l}\text { Hands-on } \\
\text { experience in a } \\
\text { coding } \\
\text { environment } \\
\text { Text processing, } \\
\text { Image } \\
\text { processing }\end{array}$ \\
\hline $\begin{array}{l}\text { Knowledge } \\
\text { Comprehension }\end{array}$ & & & $\begin{array}{l}\text { Overview of } \\
\text { Deep learning } \\
\text { models }\end{array}$ & 6 & $\begin{array}{l}\text { Anaconda, } \\
\text { Spyder. Github }\end{array}$ & $\begin{array}{l}\text { Understanding } \\
\text { of Activation } \\
\text { Functions, } \\
\text { Wights, Back } \\
\text { Propogation, } \\
\text { Neural } \\
\text { Networks(ANNs } \\
\text {, CNNs, etc), } \\
\text { and Deep } \\
\text { Learning(DL) }\end{array}$ \\
\hline Analysis & $\begin{array}{l}\text { Knowledge of } \\
\text { classifications } \\
\text { and categories, } \\
\text { principles and } \\
\text { generalizations }\end{array}$ & \multirow{4}{*}{$\begin{array}{l}\text { Collection of } \\
\text { data on } \\
\text { architectural } \\
\text { problems and } \\
\text { their analysis } \\
\text { using adequate } \\
\text { techniques }\end{array}$} & $\begin{array}{l}\text { Data } \\
\text { Acquisition }\end{array}$ & 7 & Kaggle, Github & $\begin{array}{l}\text { Creating and } \\
\text { acquiring } \\
\text { datasets }\end{array}$ \\
\hline \multirow{3}{*}{ Synthesis } & \multirow{3}{*}{$\begin{array}{l}\text { Knowledge of } \\
\text { specific skills, } \\
\text { techniques, } \\
\text { methods }\end{array}$} & & $\begin{array}{l}\text { Data } \\
\text { Preprocessing } \\
\text { basics }\end{array}$ & 8 & Kaggle, Github & $\begin{array}{l}\text { Filling up gaps } \\
\text { and cleaning up } \\
\text { features and data }\end{array}$ \\
\hline & & & \begin{tabular}{|l} 
Computer \\
Vision(CV) \\
basics \\
\end{tabular} & 9 & Kaggle, Github & $\begin{array}{l}\text { Understanding } \\
\mathrm{CV} \text { with hands- } \\
\text { on experiences }\end{array}$ \\
\hline & & & $\begin{array}{l}\text { Building } \\
\text { Learning } \\
\text { Models }\end{array}$ & 10 & Kaggle, Github & $\begin{array}{l}\text { GANs, ANNs, } \\
\text { CNNs, DLs }\end{array}$ \\
\hline Evaluation & $\begin{array}{l}\text { Strategic } \\
\text { Knowledge on } \\
\text { cognitive tasks } \\
\text { and self- } \\
\text { knowledge }\end{array}$ & $\begin{array}{l}\text { Evaluation of } \\
\text { results by } \\
\text { sensitivity } \\
\text { analyses. }\end{array}$ & $\begin{array}{l}\text { Data } \\
\text { Visualization }\end{array}$ & 11 & $\begin{array}{l}\text { Kaggle, } \\
\text { MatPlotLib, } \\
\text { heatmaps, } \\
\text { Tableau }\end{array}$ & $\begin{array}{l}\text { Understanding } \\
\text { of MatPlotLib, } \\
\text { heatmaps, etc } \\
\text { libraries for } \\
\text { evaluation and } \\
\text { visualization } \\
\text { purposes. } \\
\text { Introduction to } \\
\text { tableau software }\end{array}$ \\
\hline
\end{tabular}

There is no physical output involved in this model thus it does not aim to create a physical robot that learns Architecture. The main focus is based on a learning method. It is aimed to fill the gap in the scientific analysis regarding the learning models of the application of the architectural profession. Also, a methodological concern is to search for a logical framework that will allow sub-processes (Table 3) of architectural applications to be subject to objective definition-measurement-evaluation. The course is expected to gradually build a data collection that can be analyzed in various phases of architectural workflows. 
Table 3. Architectural workflow sub-processes and tasks analysis diagram

\begin{tabular}{|c|c|c|c|c|c|c|}
\hline \multicolumn{7}{|c|}{ Modeling of Sub-Processes in Architectural Design Workflow } \\
\hline \multicolumn{3}{|c|}{ Phases } & Content & Input & Process & Output \\
\hline \multirow{10}{*}{ 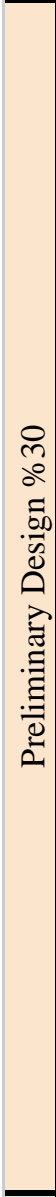 } & \multirow[b]{3}{*}{ GRASP } & \multirow{2}{*}{\begin{tabular}{|l} 
Problem \\
Definition \\
\end{tabular}} & $\begin{array}{l}\text { Communication with the } \\
\text { Client, Briefing }\end{array}$ & \multirow{3}{*}{$\begin{array}{l}\text { Clients' } \\
\text { needs, User } \\
\text { needs, } \\
\text { Building } \\
\text { Program }\end{array}$} & \multirow{14}{*}{$\begin{array}{l}\text { Acquisition of } \\
\text { - information } \\
\text { and documents: } \\
\text { Title deeds etc- } \\
\text { - Site location } \\
\text { and plans. } \\
\text { - All necessary } \\
\text { licenses, } \\
\text { numbers, and } \\
\text { dates of sites or } \\
\text { existing } \\
\text { buildings } \\
\text { - Mapping of the } \\
\text { site }\end{array}$} & \multirow[b]{3}{*}{$\begin{array}{l}\text { Design Intent } \\
\text { Definition } \\
\text { Tasks }\end{array}$} \\
\hline & & & Preliminary contract & & & \\
\hline & & $\begin{array}{l}\text { Discovery of } \\
\text { restrictions }\end{array}$ & $\begin{array}{l}\text { Site visit, Site analysis, } \\
\text { Codes analysis } \\
\text { Budget constraints }\end{array}$ & & & \\
\hline & \multirow{4}{*}{\begin{tabular}{|l} 
\\
\\
Conceptual \\
Design/ \\
Schematic \\
Design
\end{tabular}} & $\begin{array}{l}\text { Design Draft } \\
\text { for the Client }\end{array}$ & $\begin{array}{l}\text { Research, Site analysis } \\
\text { reflected onto a preliminary } \\
\text { design, Mass study, Cost } \\
\text { estimation, Concept } \\
\text { presentation work }\end{array}$ & \multirow{4}{*}{$\begin{array}{l}\text { Context, } \\
\text { Zoning } \\
\text { Typology, } \\
\text { ideology, } \\
\text { etc. }\end{array}$} & & \multirow{4}{*}{\begin{tabular}{|c} 
\\
\\
Conceptual \\
design Tasks
\end{tabular}} \\
\hline & & $\begin{array}{l}\text { Client } \\
\text { Presentation }\end{array}$ & $\begin{array}{l}\text { Presenting to the Client and } \\
\text { Getting Feedback }\end{array}$ & & & \\
\hline & & & $\begin{array}{l}\text { Evaluation/interpretation of } \\
\text { Client feedback }\end{array}$ & & & \\
\hline & & $\begin{array}{l}\text { Concept Drafts } \\
\text { (n times) }\end{array}$ & $\begin{array}{l}\text { Site massing study, site } \\
\text { plans, elevations, etc, } \\
\text { Feasibility reports, Concept } \\
\text { presentation }\end{array}$ & & & \\
\hline & \multirow[b]{3}{*}{$\begin{array}{l}\text { Design } \\
\text { Development }\end{array}$} & $1 / 500$ & Site Plan & \multirow{3}{*}{$\begin{array}{l}\text { Circulation } \\
\text { elements, } \\
\text { Levels, etc. } \\
\text { Spaces, } \\
\text { materials } \\
\text { Structural } \\
\text { design } \\
\text { project. }\end{array}$} & & \multirow[b]{3}{*}{$\begin{array}{l}\text { Iterative } \\
\text { Design } \\
\text { Output Tasks } \\
\end{array}$} \\
\hline & & $1 / 100,1 / 200$ & $\begin{array}{l}\text { Floor plans, Sections, } \\
\text { Elevations }\end{array}$ & & & \\
\hline & & N/A & $\begin{array}{l}\text { Specifications, Budget, } \\
\text { Sharing with shareholders, } \\
\text { Client approval, Building } \\
\text { Permit }\end{array}$ & & & \\
\hline \multirow{4}{*}{ 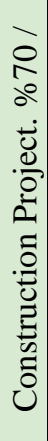 } & & Floor Plans & $\begin{array}{l}\text { Structural Elements, Gridal } \\
\text { Axes, Wet spaces, Slab } \\
\text { details, etc. }\end{array}$ & \multirow{4}{*}{$\begin{array}{l}\text { Electrical, } \\
\text { mechanical, } \\
\text { plumbing, or } \\
\text { central } \\
\text { heating) } \\
\text { system } \\
\text { Stairs, } \\
\text { Suspended } \\
\text { Ceilings, } \\
\text { Wallpapers, } \\
\text { etc. }\end{array}$} & & \multirow[b]{4}{*}{$\begin{array}{l}\text { Solid/Concre } \\
\text { te Design } \\
\text { Output Tasks }\end{array}$} \\
\hline & $1 / 50$ & MEP Projects & $\mathrm{A} / \mathrm{R}$ & & & \\
\hline & $1 / 20$ & System Details & $\mathrm{A} / \mathrm{R}$ & & & \\
\hline & $\begin{array}{l}1 / 10,1 / 5 \\
1 / 2,1 / 1\end{array}$ & $\begin{array}{l}\text { Fabrication/ } \\
\text { construction } \\
\text { Details }\end{array}$ & $\mathrm{A} / \mathrm{R}$ & & & \\
\hline
\end{tabular}

\subsection{Course Objectives}

The course aims to deliver a basic level of information on artificial intelligence and to discuss the possible contributions of artificial intelligence implementations to architectural problem-solving practices.

The Objectives were to upskill the students to; 1. Conduct research on AI and Machine Learning (ML) within the context of architectural design. 2. Envision AEC, and specifically architectural design processes through the analysis of tasks that constitute the whole process. 3. Perform simple AI applications that can be transformed into architectural processes. 4. Enhance their critical understanding of the dismantling of their profession. [53] 


\subsection{Student Characteristics}

Practical issues were important when designing the details of the elective course exploring the Artificial Intelligence tools and techniques on Architectural Intelligence: Artificial Intelligence in Architecture. An informal conversational survey was done with potential students before the course proposal; 1 . The students had little or no coding experience. 2 . The majority of students/audience were not specifically interested in AI tools and techniques but rather were generally curious about the intense interest in AI. 3 . The students mainly preferred to work in teams throughout the semester. 4 . There were no teaching assistants assigned by the institutions. Volunteering TA's were assigned and briefly trained by the instructor.

\subsection{Content Delivery}

The teaching mode of the course is a hybrid of teacher-led and learner-based approaches [54]. The content was delivered in lectures of approximately one hour, followed by practice sessions that focused on weekly assignments. The learning scenario exercised in this course displays an approach for introducing AI tools, techniques, and concepts to students of architecture. The main goal was to show students the implications for the implementation of AI in architectural design workflows. The tasks assigned to students were designed to encourage self-learning. The course covered main topics as; 1 . Possible contributions of artificial intelligence implementations to architectural problem-solving practices, 2. Training principles of artificial intelligence and role and significance of data towards solving architectural problems, 3. Collection of data on architectural problems and their analysis using adequate techniques, 4. Evaluation of results by sensitivity analyses.

As the domain grows very rapidly the course gets updated simultaneously. For example, the previous two semesters did not cover the use of GAN's in Architecture although the model has been introduced as the state-of-the-art application for deep learning. Therefore GANs and CNNs that run on various datasets that did not necessarily involve architectural matter were included among the weekly assignments. However, the newer applications mentioned above are included in the current content.

In the introduction, students in pairs were assigned to conduct an in-class research project to define "Intelligence". The groups were expected to prepare a presentation and define the term based on different aspects, ranging from the word "intellect" to its meaning in the phrase intelligence agencies, from their ideas to the findings/discussions in their research. This assignment provided a warm-up to focus on the meaning of AI.

In the Second Assignment, students had hands-on experience in a coding environment. They were expected to download and install Anaconda Navigator, launch Jupyter, create a folder on their desktop, create a new Python 3 file and write the code that they were given. They were also given extended time to create variations of the code provided.

Assignment \#3a (Figure 1) was on Computer Vision. The class was given step-by-step instructions for setting up their environments and updating channels within Anaconda and starting Spyder. The codes in .py files were provided with the Assignment, and the .xml files needed for the model were downloaded from github.com, through provided links. Students were encouraged to find their way around Github and their computer's operating systems and were later given support for actions including using Anaconda Prompt. When successful in running the codes in Spyder, and use of the Computer Vision application, they were expected to modify the code with different lines and then receive another additional object recognition instance, as the second part of the assignment. 


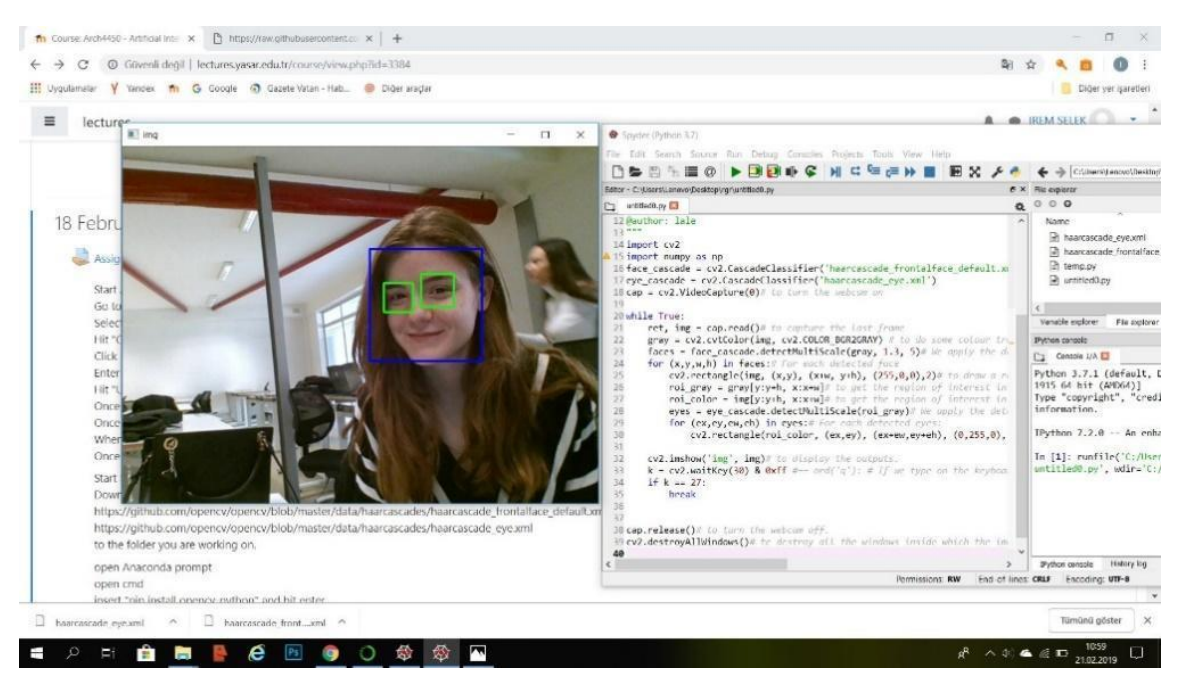

Figure 1. Assignment on Computer Vision. The class was given step-by-step instructions for setting up their environments and updating channels within Anaconda and starting Spyder

Following the coding exercises, the students were asked to run research on the converging scene of Architecture and Computer Science. In pairs, they selected a visionary, from a list, for thorough research, to understand the interdisciplinary nature of their work. As an output, they were expected to respond to questions concerning the main pursuit of the visionary, how they were influenced by the converging disciplines that they had mastered, and their main contribution to the field of Architecture.

Assignment \#6 was designed as an additional exercise to introduce a useful piece of software for data visualization. Aside from students' models built previously in class for data visualization, the software was introduced to allow the students to explore and interpret the data within a familiar visual environment.

The first Midterm was designed as a written Q\&A format drawing on the content of weekly lectures, and the students' interpretations on AI and Architectural domains. Exercises were designed to encourage explorations on current applications, and students accessed experiments on AI through the links provided. The links prevented students from losing focus and scope, although they were also allowed to use their sources. Additionally, they were given readings to try and understand how the sketch drawings are represented to implement the algorithm needed for Neural Networks in the task of sketching. The materials given to the students framed the experimental work and research run on AI in design domains in several educational institutions and leading technology companies. The purpose of this assignment was to highlight the connections between students' projects in progress and these experimentations.

In the first phase of Midterm \#2, they were asked to describe the steps to instruct a hypothetical apprentice robot. Previously, the students had been introduced to a project called "X", an AI assistant learning to be an architect. Their task was to give $\underline{X}$ the design workflow (Figure 2 ) including all tasks and steps of architectural practice. This involved listing and assigning all the tasks that an architectural design process requires, for the AI assistant to be trained. The list could be iterative or might contain loops. 


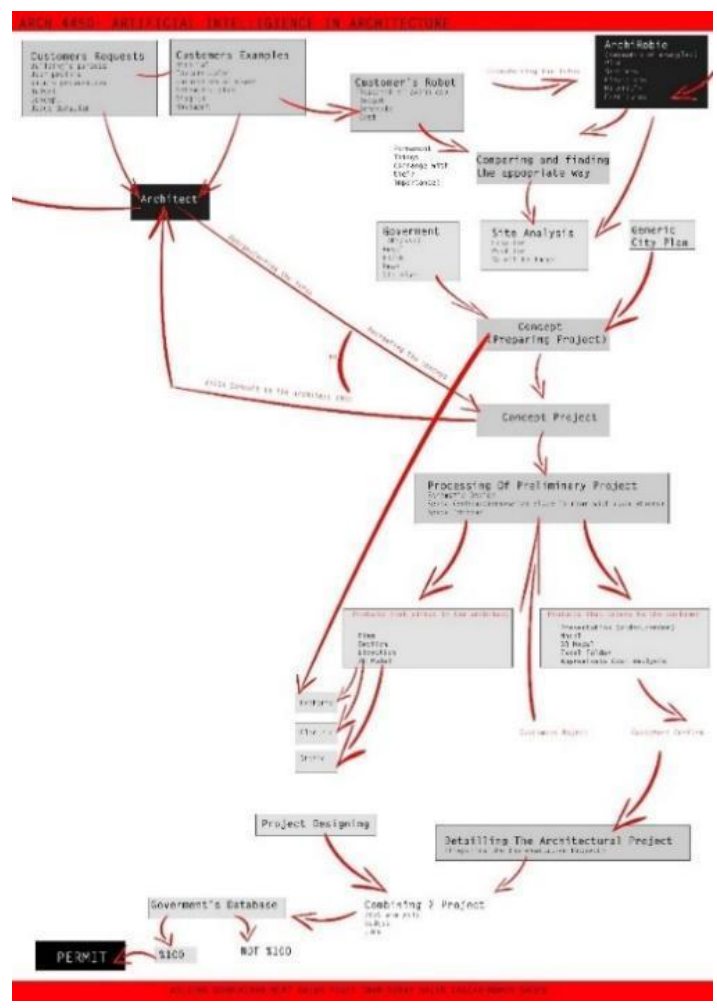

Figure 2. Design workflow including all tasks and steps of architectural practice

Since the research domain of the course covers the workflow processes of the architectural practice, it is necessary to mention this workflow which is previously defined as sub-processes. Although the architect's tasks and workflow processes may vary, a general workflow can be addressed at the higher level (Table1). Starting upon the expression and announcement of the architectural project as a problem definition, the flow continues with the perception and diagnosis of the problem. This process is detailed within this assignment.

The second phase is aimed at focusing on a specific part within the workflow, with the instruction "Zoom in on one step of the process". They were asked to choose the part of the workflow that was most appealing/motivating for them, and define what type of algorithm and data would help them instruct $\underline{X}$ within that part of the workflow (eg. Listening to the Client: Natural Language Processing or Speech Recognition algorithms to read data acquired from the audio file of clients' describing the project)

The analyses for each phase of the project contributed to the students' understanding of architectural design processes. For example, the first step of the workflow, selected by the majority of the students, was the briefing stage. In practice, during this initial stage, in many project management cases, approximately $80 \%$ of the costs are anticipated [55]. This stage is also important for determining construction issues including costs [56].

Therefore, in this stage of understanding, the problem carries vital importance. However, some studies define success during this stage as the structuring and formulation of the problem. Therefore, expertise in design is attributed to being solution-focused rather than problem-focused, and problem framing is favored during the initial stages of design workflow [57].

The Final assignment was designed in two stages and was announced early in the semester. The first phase was to build their dataset. Students were encouraged to work in groups of four, but were allowed to work alone if they preferred. A template containing features/values/variables etc. was provided for the dataset files. 
In the final phase, students were expected to use the collectively-prepared dataset using a "Taxonomy of tasks for AI in Architecture" for the definition of tasks (Table 1). Since this taxonomy is provided to help the students analyze architectural design processes by classifying each task, they were expected to fill out the forms in detail in their final assignment. "Classification of Tasks" allows the students to identify whether the task in concern requires human intervention (RHI) and whether it can be learned by the model (AI) or it can be defined as a routine task that can be automatized (RPA).

A submission to demonstrate how the taxonomy of tasks is filled out can be viewed in Figure 4. Upon identification of tasks, the students were invited to work on the online platform called Kaggle that they were previously experienced with and were additionally provided with instructions on how to load their datasets, and also with template models to preprocess their data, through weekly assignments. As an essential part of the final assignment, the students were expected to have filled out the form and come up with a model to perform the tasks they focused on and analyzed within the architectural design workflow. The form of submission for the models was either notebooks (Figure 3) or scripts that ran on Kaggle or within Anaconda.

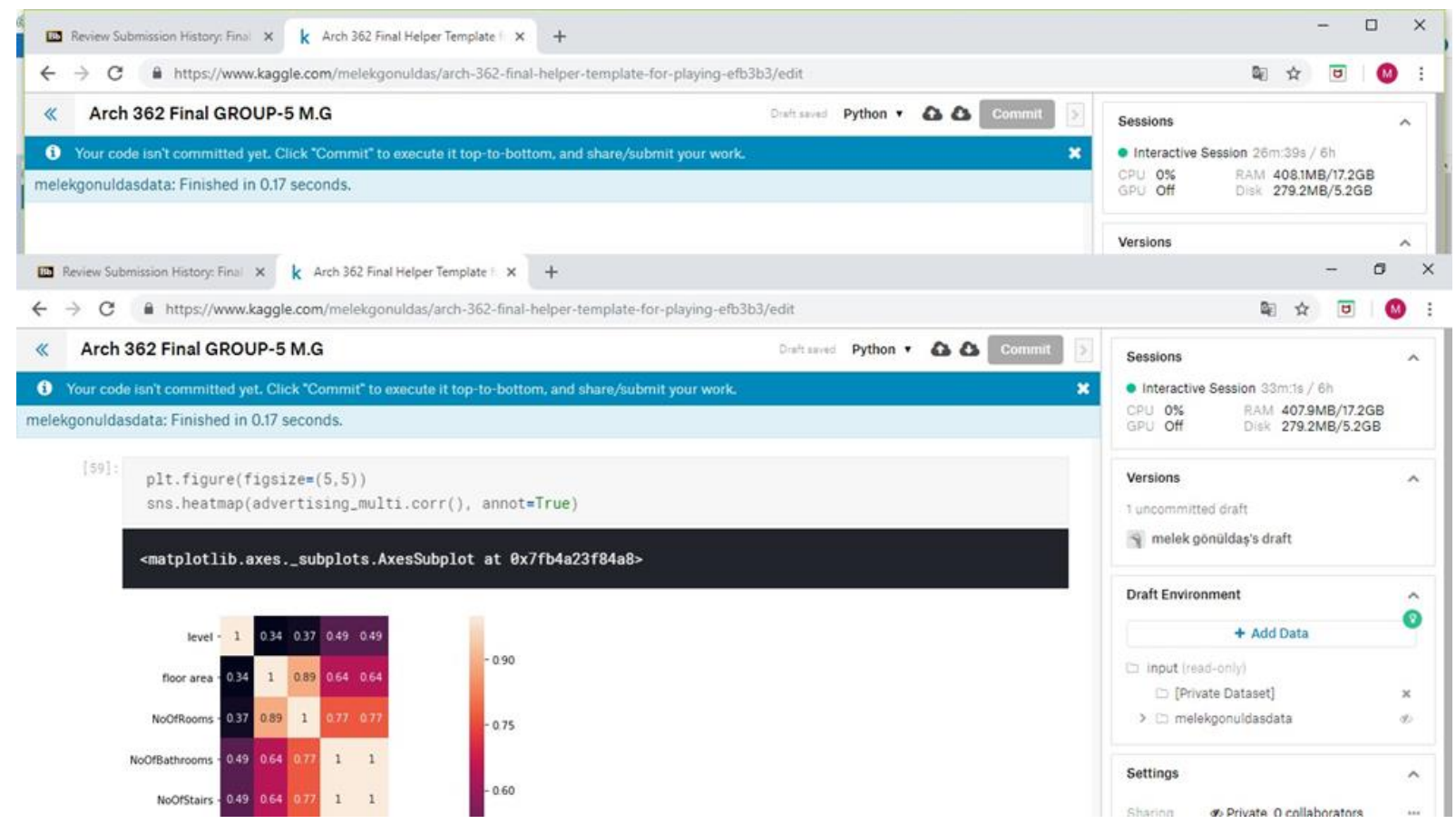

Figure 3. Kaggle Notebook displaying students' models' evaluation 


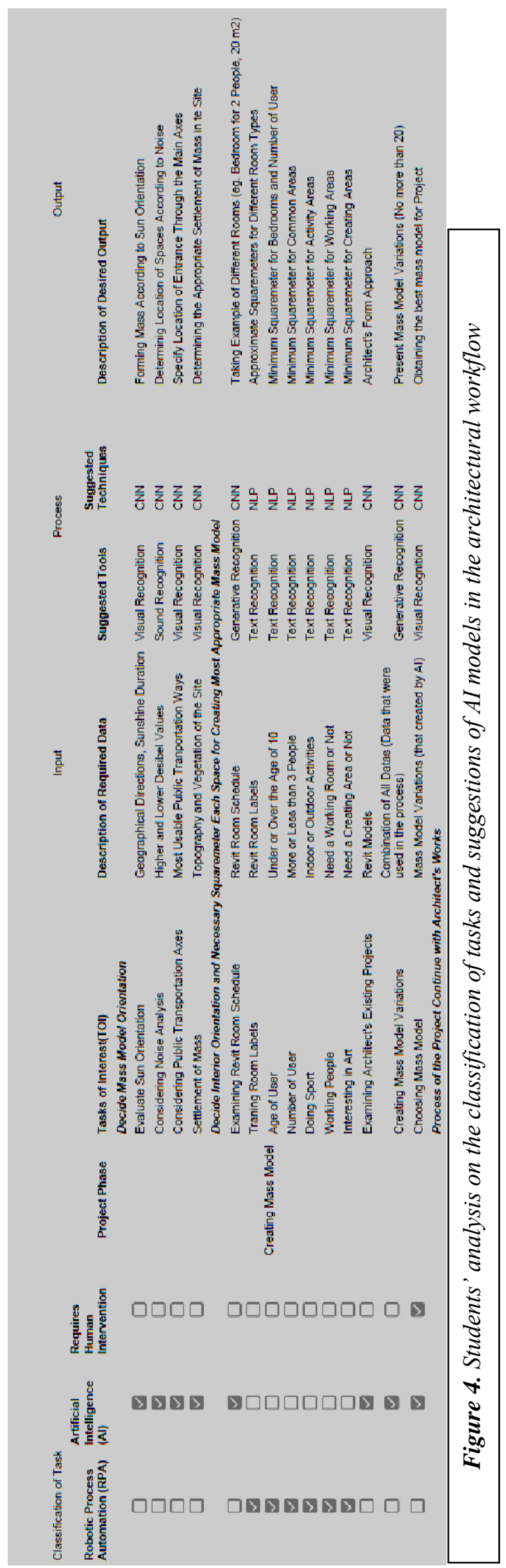




\section{SUMMARY AND DISCUSSION}

A similar course with a similar title, but prepared with different content and objectives, was coded as Arch $\mathrm{x}$ in $X^{\prime}$ University. This course was designed to be a three-hour elective, offering one hour of theory and two hours of practice. The syllabus was revised by the author to fit curricular requirements to have similar learning outcomes. The paper does not attempt to compare the two courses since they were not run under the same conditions, but instead, analyze, discuss, and describe the overall experience, performance, and impact of the course within a pedagogical context. The scope of the paper is limited to introducing the course as a pedagogical model for integrating AI into the Architectural curriculum.

Although this course is designed to allow sufficient time to accommodate hands-on experience, tasks such as running algorithms, modifying codes, loading new libraries, and searching for adequate datasets, are by nature challenging and time-consuming. Therefore, the assignments were prepared with the consideration of these aspects, which somewhat prevented students from experiencing the full challenges of preparing datasets and/or deciding on which techniques and tools were more appropriate for which problems.

Students were not comfortable, due to a lack of coding skills. The course would be more productive for students with proficiency in the Python language. However, the course objective is to enable students to become code-literate architectural designers, rather than programmers. There is therefore a claim from GitHub that the future of coding will not require coding by humans [58], however for the time being coding skills or at least code literacy boost understanding AI in practice.

Once the students became accustomed to a completely new learning environment and were able to build upon newly acquired knowledge and practices, they became more motivated to learn new tools and techniques. Working in groups of two to four, depending on the type of assignments, greatly reduced the anxiety about technical aspects for the majority. Time restriction appeared as a factor preventing students from becoming immersed in problem-solving processes concerning daily assignments. The majority of AI tools and techniques were not originally designed for architecture. At the end of the courses, the students evaluated the courses. 36 out of 38 registered students taking the course voted for an average score of 4,31 points out of 5 for an evaluation of learning outcomes of the course (Figure 5).

\begin{tabular}{|lll|}
\multicolumn{1}{l}{ Öğrenme Çıktı Ortalamaları } \\
\hline No & Öğrenme Çıktısı & Ortalama \\
\hline 1 & Students will familiarize themselves with the use of computational methods for approaching and solving design problems. & 4,34 \\
\hline 2 & Students will gain knowledge with respect to formulating problems, evaluating designs, searching for solutions. & 4,37 \\
\hline 3 & Students will gain overview of available approaches to support decision making through computation in design: Artificial Neural Networks, etc. & 4,29 \\
\hline 4 & Students will comprehend the role of data in artificial intelligence & 4,29 \\
\hline 5 & Students will learn to prepare a report of their work in the proper scientific attitude and format & 4,26 \\
\hline
\end{tabular}

Figure 5. Students' evaluation results for learning outcomes

In attempting to solve the major problems of designing for a rapidly changing society, it may be that we are neglecting some fundamental aspects of education for architectural practice thereby weakening our position professionally. AI may augment architects in uncovering and quantifying the tacit knowledge of architecture. Since the definition of objectives is an essential prerequisite to the formulation of an educational program, schools must work closely with the profession. In times of rapid change, the essential requirements are imagination, flexibility, and encouragement. Teaching machines to simulate human skills requires that each feature is finely described. These human skills are using language, forming abstractions and concepts, and solving problems [59]. To implement human cognition in machines, humans still need to develop the power of abstraction and reasoning (extreme generalization) versus the power of pattern recognition (local generalization) [60]. 


\section{CONCLUSION}

The experimentation rendered above presents a case study of exploring the tools and techniques of AI while searching for their potential use in architectural design processes within the scope of an inputprocess-output model as defined in the taxonomy for AI in Architecture.

Proposing the appropriate strategies for AI education in architectural design education is both complex and challenging. AI is a broad domain that needs a definitive purpose since it has a wide variety of tools and applications. These tools and applications require practice to determine which of them are appropriate for specific tasks and learning processes. Therefore, it is challenging to select the scope of teaching content in terms of AI theory and practice.

Considering the current research gap, it appears that the following research questions need to be answered: 1. What are the present trends and professional changes affecting architectural education? 2 . What skillset should prospective architects have to understand user data, integrate machine learning applications in the design process, and identify corresponding architectural solutions? 3. How can AI help the architectural practice to quantify and understand client's needs, and build a framework to accommodate tacit knowledge to predict and suggest solutions where appropriate?

The goal of this course and the search for an AI to imitate Architects does not necessarily aim to nudge the architect towards extinction. Rather, it is to create a refined definition of all tasks involved within the workflow and understand human cognitive processes [61].

Because of the changing nature of the architectural profession due to technological advancements, an appropriate pedagogical model was developed and explored. The paper displayed the flow of the course based on its iteratively updated teaching and assessment strategies. However, further discussion in educational institutions is needed to evaluate and understand the possible impact of $\mathrm{AI}$ in architecture. A wide range of reasons students have to register for elective courses vary from the interest in the subject to the anticipated class size. Other criteria include workload, the difficulty of the course, and grading system, and the personality of the instructor [62]. This course is no exception.

Finally, the author would argue that the course might be more fruitful soon when more experimentation on AI models from the architectural domain is integrated into the course.

\section{ACKNOWLEDGMENTS}

In 2017 the course named "Architectural Intelligence: Artificial Intelligence in Architecture" was suggested by the author as a five-hour elective course to the architectural department of XUniversity in 2017 and was accepted and coded as Arch X. This course started in the fall of 2018. The author would like to thank the students and fellow faculty who contributed to this experimental education setup by engaging in all stages of the course and encouraging this article.

\section{CONFLICTS OF INTEREST}

No conflict of interest was declared by the author.

\section{REFERENCES}

[1] Ra, S., Shrestha, U., Khatiwada, S., Seung, W. Y., Kwon, K., "The rise of technology and impact on skills", International Journal of Training Research, 17: 26-40, (2019).

[2] Gerber, B. B., Gerber, D. J., Ku, K., "The pace of technological innovation in architecture, engineering, and construction education: integrating recent trends into the curricula", Journal of Information Technology in Construction (ITcon), 16: 411-432, (2011). 
[3] Woo, J. H., "BIM (Building Information Modeling) and Pedagogical Challenges", Proceedings of the 43rd ASC National Annual Conference Flagstaff, AZ, April 12-14, (2006).

[4] Boeykens, S., De Somer, P., Klein, R., Saey, R., "Experiencing BIM collaboration in education Computation and Performance", Proceedings of the 31st Education and Research in Computer Aided Architectural Design in Europe Conference (eCAADe), Delft University of Technology, Delft, The Netherlands, 505-513, (2013).

[5] Sacks, R., Girolami, M., Brilakis, I., "Building Information Modelling, Artificial Intelligence and Construction Tech", Developments in the Built Environment, 4, (2020).

[6] Tepavčević, B., "Design thinking models for architectural education", The Journal of Public Space, 2(3): 67-72, (2017).

[7] Ghonim, M., Eweda, N., "Investigating elective courses in architectural education", Frontiers of Architectural Research, 7: 235-256, (2018).

[8] Polanyi, M., and Sen, A., "The tacit dimension", University of Chicago Press, (1966, 2009).

[9] Koçyiğit, R.G., "Bilgi Kuramı Bağlamında Mimarlık Bilgisi ve Mimarlıkta Bilimsellik Sorunu", Mimarlık, Planlama ve Tasarım Araştırmaları, 25-41, (2018).

[10] Glick, E., “Two Methodologies for Evaluating Intellectualism”, Philosophy and Phenomenological Research, 83(2): 398-34, (2011).

[11] Yan, D., O’Brien, W., Hong, T. Z., Feng, X. H., Gunay, H. B., Tahmasebi, F., Mahdavi, A., "Occupant behavior modeling for building performance simulation: Current state and future challenges", Energy and Buildings, 107: 264-278, (2015).

[12] Ornetzeder, M., Wicher, M., Suschek-Berger, J., "User satisfaction and well-being in energyefficient office buildings: Evidence from cutting-edge projects in Austria", Energy and Building, 118: 18-26, (2016).

[13] Friedman, Y., "Toward a Scientific Architecture”, MIT Press, (1980).

[14] Burry, M., "Scripting Cultures: Architectural Design and Programming”, Wiley, Chichester, UK, (2011).

[15] Alexander, C., Ishikawa, S., Silverstein, M., “A pattern language”, New York: Oxford University Press, (1977).

[16] Başarır, L., Erol, K., "Briefing AI: From Architectural Design Brief Texts to Architectural Design Sketches", The 9th ASCAAD International Conference, 1: 23-31, (2021).

[17] Gero, J. S., "Special Issue: Artificial intelligence in computer-aided design: Progress and prognosis", Computer-Aided Design, 26(3): 153-154, (1996).

[18] Bier, H., Cheng, A. L., Mostafavi, S., Anton, A., Bodea, S., "Robotic Building as Integration of Design-to-Robotic-Production and -Operation", In H. Bier, Robotic Building, Springer International Publishing, 97-119, (2018). 
[19] Eastman, C. M., “Automated space planning”, Artificial Intelligence, 4(1): 41-64, (1973).

[20] Liggett, R. S., "Automated facilities layout: past, present, and future", Automation in Construction: 197-215, (2000).

[21] Muther, R., Hales, L., "Systematic Layout Planning", Marietta: Management \& Industrial Research Publications, (2015).

[22] Calixto, V., Celani, G., "A literature review for space planning optimization using an evolutionary algorithm approach: 1992-2014”, Generative Systems: 662-671, SIGRADI, (2015).

[23] Mitchell, W. J., "A Computer-Aided Approach to Complex Building Layout Problems", Proceedings of EDRA2 Conference, (1970).

[24] Gero, J. S., "Special Issue: Artificial intelligence in computer-aided design: Progress and prognosis", Computer-Aided Design, 26(3): 153-154, (1996).

[25] Burry, M., "Scripting Cultures: Architectural Design and Programming”, Wiley, Chichester, UK, (2011).

[26] Leach, N., "Design in the Age of Artificial Intelligence", Landscape Architecture Frontiers/papers, APRIL 2018, 6 (2): 9-19, (2018).

[27] Marks, M., "Construction: The next great tech transformation", Voices June, (2017).

[28] Basarir, L., "What if AI Apprentices Outperform Their Human Counterparts?", Journal of Computational Design, 1 (3): 153-166, (2020).

[29] Tamke, M., Nicholas, P., Zwierzyck, M., "Machine learning for architectural design: Practices and infrastructure", International Journal of Architectural Computing, 16(2): 123-143, (2018).

[30] Huang, W., Zheng, H., "Architectural Drawings Recognition and Generation through Machine Learning", The38th Annual Conference of the Association for Computer Aided Design in Architecture, Mexico City: ACADIA2018: 156-165, (2018).

[31] Chaillou, S., "Architecture \& Style: A New Frontier for AI in Architecture", Towards Data Science, (2019).

[32] Negroponte, N., “The Architecture Machine”, Computer Aided Design, 7(3): 190 - 195, (1975).

[33] Stiny, G., Gips J., "Shape grammars and the generative specification of painting and sculpture", in Information Processing 71 (North-Holland, Amsterdam), 1: 1460-1465, (1972).

[34] Stiny, G., "Introduction to shape and shape grammars", Environment and Planning B, 7: 343-351, (1980).

[35] Mitchell, W.J., "The Logic of Architecture: Design, Computation, and Cognition”, First Edition, MIT Press, Cambridge, MA, USA, (1990).

[36] Coyne, R. D., Rosenman M. A., Radford, A.D., Balachandran, M., Gero, J.S., "Knowledge-based design systems", Addison Wesley, 567, (1990). 
[37] Mustoe, J.E.H., "Artificial Intelligence and Its Application in Architectural Design”, Dissertation, Department of Architecture and Building Science, University of Strathclyde, Glasgow, (1990).

[38] Silva, N.F., Bridges, A.H., "Human-Computer Interaction and Neural Networks in Architectural Design”, In: Junge R. (eds) CAAD futures 1997, Springer, Dordrecht, 267-284, (1997).

[39] Belém, C., Santos, L.M., Leitão, A., "On the Impact of Machine Learning: Architecture without Architects?", (2019).

[40] Cudzik, J., Radziszewski, K., “Artificial Intelligence Aided Architectural Design”, Proceedings of the 36th eCAADe Conference, 1: 77-84, (2018).

[41] Huang, W., Zheng, H., "Architectural Drawings Recognition and Generation through Machine Learning", The 38th Annual Conference of the Association for Computer-Aided Design in Architecture, Mexico City: ACADIA2018, 156-165, (2018).

[42] Chaillou, S., "Architecture \& Style: A New Frontier for AI in Architecture", Towards Data Science, (2019).

[43] Isola, P., Zhu J.Y., Zhou, T., Efros, A.A., "Image-to-Image Translation with Conditional Adversarial Networks", Arxiv, (2016).

[44] Kulcke, M., "Design-Bot - Using Half-Automated Qualitative Interviews as Part of Self Communication within the Design Process", Proceedings of the 36th eCAADe Conference , 1: 103-108, (2018).

[45] Başarır, L., Erol, K., "Briefing AI: From Architectural Design Brief Texts to Architectural Design Sketches", The 9th ASCAAD International Conference, 1: 23-31, (2021).

[46] Ramesh, A., Pavlov, M., Goh, G., Gray, S., Voss, C., Radford, A., Chen, M., Sutskever, I., "Zero-Shot Text-to-Image Generation", ArXiv, abs/2102.12092, (2021).

[47] Alexander, C., Ishikawa, S., Silverstein, M., “A pattern language”, New York: Oxford University Press, (1977).

[48] Mitchell, M., “Artificial Intelligence Hits the Barrier of Meaning”, Information, 10(2): 51, (2019).

[49] Sagar, M., Seymour, M., Henderson, A., "Creating Connection with Autonomous Facial Animation", Communications of the ACM, 59(12): 82-91, (2016).

[50] Susskind, D., Susskind, R., "The Future of the Professions", Proceedings of the American Philosophical Society, Oxford: American Philosophical Society, 162: 125-138, (2018).

[51] Wrigley, C., Straker, K., "Design thinking pedagogy: The educational design ladder", Innovations in Education and Teaching International, 54(4), 374- 385, (2017).

[52] Teymur, N., "Learning Housing Designing", in Bulos, M., and Teymur, N., (eds): Housing: Design Research Education, Aldershot, Avebury, 3-27, (1993).

[53] University, Y., "Arch 4450- Artificial Intelligence in Architecture (Elective Course)" 2018-2019Academic-Year-Curriculum: $\quad$ https://arch.yasar.edu.tr/en/wp-content/uploads/2018/09/2018- 
2019-Akademik-Y\%C4\%B11\%C4\%B1-M\%C3\%BCfredat\%C4\%B1.pdf (2018). Retrieved on September 22, 2019

[54] Biggs, J., Tang, C., "Teaching for quality learning at university", Third Edition, Maidenhead: Society for Research into Higher Education \& Open University Press, (2007).

[55] Bruce, M., Cooper, R., "Creative product design: a practical guide to requirements capture management", Chichester, New York: Wiley, (2000).

[56] Allan, N., Godfrey, P., "CRISP (2001) Issues on the early stages of construction projects", CRISP Commission-00/8. London: University of Bristol and Halcrow Group Limited, (2001).

[57] Cross, N., "Expertise in design: an overview", Design Studies, 25(5): 427-441, (2004).

[58] AI Forces Shaping Work \& Learning in 2030, Report on Expert Convenings for a New Work \& Learn Future, Lumina Foundation, 42, (2018).

[59] McCarthy, J., Minsky, M. L., Rochester, N., Shannon, C., "A Proposal for the Dartmouth Summer Research Project on Artificial Intelligence”, 0-13, (1955).

[60] Chollet, F., "Deep Learning with Python”, New York, NY: Manning Publications, (2018).

[61] Cross, N., "Can a Machine Design?”, Design Issues, 17(4), 44-50, (2001).

[62] Ting, D. H., Lee, C. K., "Understanding students' choice of electives and its implications", Studies in Higher Education, 37(3): 309-325, (2012). 